\title{
YieldCurve.com
}

\section{THE IMPACT OF OPTION STRATEGIES IN FINANCIAL PORTFOLIOS PERFORMANCE: MEAN-VARIANCE AND STOCHASTIC DOMINANCE APPROACHES}

\author{
Fathi Abid \\ Professor of Finance \\ University of Sfax: UR: MO.DE.S.FI \\ Faculty of Business and Economics of Sfax, TUNISIA \\ Fathi.Abid@fsegs.rnu.tn \\ $+21674278777$ \\ $+21674279139$ \\ Mourad Mroua \\ Associate Assistant Professor \\ University of Sfax: UR: MO.DE.S.FI \\ Faculty of Business and Economics of Sfax, TUNISIA \\ $\frac{\text { Mroua_Mourad@yahoo.fr }}{+21698656786}$ \\ Wing-Keung Wong \\ Associate Professor \\ Department of Economics \\ Faculty of Arts and Social Sciences \\ National University of Singapore, 1 Arts Link, Singapore 117570 \\ (65) $874-6014$ \\ (65) $775-2646$ \\ ecswwk@nus.edu.sg \\ This version: August 2005 \\ Received: March 2006
}




\title{
THE IMPACT OF OPTION STRATEGIES IN FINANCIAL PORTFOLIOS PERFORMANCE: MEAN-VARIANCE AND STOCHASTIC DOMINANCE APPROACHES
}

\begin{abstract}
This study employs the mean-variance (MV) criterion, Capital Asset Pricing Model (CAPM) statistics and stochastic dominance (SD) analysis to investigate the performance of option strategies, including writing out-of-the-money (OTM) covered call and buying in-the-money (ITM) protective put, with that of the pure-stock investment by analysing the French data in the entire 1999 year. Our results from MV criterion show that none of these three strategies dominate one another but our CAPM statistics show that in general buying ITM protective-put strategy obtains the highest performance, followed by the writing OTM covered-call strategy while the naked stock obtains the smallest values. This confirms the superiority of ITM protective-put strategy, followed by OTM covered-call strategy by using the Beta coefficient, Sharpe ratio, Treynor and Jensen indices.
\end{abstract}

As the return distributions of these strategies are non-normal, the MV criterion and the CAPM statistics may not be appropriate to assess the relative performance measurement of the portfolios. We further investigate the performance by employing SD approach. Our SD findings reveal that most of the buying covered-call and writing protective-put strategies are superior to their corresponding pure-stock strategy, as in general the former stochastically dominates the latter in the sense of first order SD. This infers that there may exist an anomaly of the existence of an arbitrage opportunity in option trading that all types of non-satiated investors will increase their wealth and utility by switching from the pure unhedged stock strategy to their corresponding buying protective-put or writing covered-call strategies. In addition, we find the dominance relationship between the two hedged positions is not as clear as the comparison with their unhedged positions, but on average more buying ITM protective put outperforms writing OTM covered call in the sense of the first-order SD. In short, our results confirm that option introduction improve significantly the performance of unhedged portfolios, especially buying ITM protective put.

Keys Words: Writing covered call option, Buying protective put option, portfolios management, mean-variance approach, nonparametric stochastic dominance test. 


\section{INTRODUCTION}

The rapid growth of the use of options in portfolio management has been accompanied by a variety of claims regarding option performance strategies. Many investors believe that they can enhance the performance of their pure-stock portfolios by incorporating different options strategies. Among them, the most popular strategies are covered-call writing and protective-put buying. In theory, there is no clear evidence on whether a specific option strategy is superior. According to the efficient market theory, an increase in returns should be accompanied by an increase in risk. Adding options to stock portfolios may also create problems of performance measurement homogeneity. Hedging is a financial transaction in which one asset is held to offset the risk of holding another asset. Typically, a hedge is used to offset price risk due to changes of financial market conditions. In this way, the development of financial derivative instruments (options, futures, forward and swap) make hedgers simple to use it to reduce risk. However, many portfolio managers use these derivative instruments to speculate instead of hedging and, in turn, increase risk. The general framework suggested by Hakanson (1978), Cox (1976) and Ross (1976) indicates that incorporating option enhances the general efficiency of financial markets by increasing the number of investment opportunities available to investors in terms of insurance and hedging, but not lead to any arbitrage opportunity.

Several studies compare the performance between unhedged and hedged positions with options or compare the performance among different hedged positions. For example, Trennepohl and Dukes (1981) investigate the performance of option writing and buying strategies using in-the-money (ITM) and out-of-the-money (OTM) options and conclude that covered option writing lowers portfolio standard deviation and improves portfolio mean returns. They also conclude that writing calls or buying puts goes along with reduction of both risk and return, compared to the unprotected stock position. Employing simulation approaches, Bookstaber and Clarke (1984) compare the performance of protective-put, covered-call, and pure-stock strategies and conclude that call writing is better than put buying as the former truncates the right-hand side of a distribution causing undesirable negative skewness while put-buying truncates the left-hand side of a distribution causing desirable positive skewness. 
In contrast to the studies of Trennepohl and Dukes (1981) and Bookstaber and Clarke (1984) using MV analysis, Dybvig and Ingersoll (1982) and Bookstaber and Clarke (1985) comment that MV analysis is not appropriate because of the change in portfolio return distributions when options are introduced. On the other hand, Booth, Tehranian and Trennepohl (1985) suggest that stochastic dominance (SD) approach is more appropriate than MV analysis in portfolio selection using option strategies and find that SD rules are useful in raking portfolios of options combined with other assets. Clarke (1991) applies the SD algorithm developed by Bookstaber and Clarke (1983) to compare the performance of several strategies (100\% stock, 100\% calls, $90 \%$ T-bills and 10\% calls, and covered-call writing and protective-put buying). He concludes that the MV approach could not be used to measure the option strategies performance and finds that option strategies do not dominate the pure-stock buy-and-hold strategy when options are fairly valued by Black and Scholes (1973) model. However, if options are somewhat mis-priced, second-degree dominance relationships appear from covered-call or protective-put strategies to pure-stock strategy. Using Swiss stocks, option and futures data, investigating the performance of a diversified strategy with option, in particular, writing covered-call strategy, Isakov and Morard (2001) reveal that option introduction leads to an increase of return and simultaneously a decrease of volatility, and their SD results show the superiority of covered to uncovered portfolios.

Nonetheless, the performance of incorporating option in stock could be due to other factors or market conditions. For example, Benninga and Blume (1985) analyse the optimality of portfolio insurance in a complete and an incomplete market. They find that buying put option may be optimal only in an incomplete market, but not in a complete market. Brooks and Hand (1988) examine the return characteristics of the new index futures contracts by analysing the performance of a portfolio that incorporates these contracts. They find that both return distribution and performance evaluation depend on the risk-free rate, the dividend rate, the basis and the margins. Besides MV or SD approaches, other approaches could also be useful in the evaluation of the performance of options and stocks. For example, employing a Value-at-Risk approach, Castellano and Giacometti (2001) compare the performance of protective-put and covered-call strategies to the performance of holding an unhedged currency portfolio and conclude that the hedged strategies perform better than the optimal naked portfolios and the protective-put strategy performs well for different VaR models. In addition, the Capital Asset Pricing Model (CAPM) statistics 
developed by Sharpe (1964), Treynor (1965) and Jensen (1969) are also widely used in the comparison of stock, option and futures performance.

The main purpose of this study is to understand the modification of the portfolio characteristics when options are added to it. This study employs the MV criterion, CAPM statistics and SD analysis to investigate the performance of option strategies, including writing OTM covered-call and buying ITM protective put, with that of the pure-stock investment by analysing the French data in the entire 1999 year. Our results in MV criterion show that none of these three strategies dominate one another but our CAPM statistics show that, in general, the buying ITM protective-put strategy obtains the highest performance, followed by the writing OTM covered-call strategy while the naked stock obtains the smallest values. This confirms the superiority of ITM protective put, followed by OTM covered-call strategy by using the Beta coefficient, Sharpe ratio, Treynor and Jensen indices.

As the return distributions of these strategies are non-normal, the MV criterion and the CAPM statistics may not be appropriate to assess the relative performance measurement of the portfolios. We further investigate the performance by employing SD approach. Our SD findings reveal that most of the buying covered-call and writing protective-put strategies are superior to their corresponding pure-stock strategy as, in general, the former stochastically dominates the latter in the sense of first order SD. This infers that there may exist an anomaly of the existence of an arbitrage opportunity in option trading that all types of non-satiated investors will increase their wealth and utility by switching from the pure unhedged stock strategy to their corresponding buying protective-put or writing covered-call strategies. In addition, we find the dominance relationship between the two hedged positions is not as clear as the comparison with their unhedged positions, but on average more buying ITM protective put outperforms writing OTM covered call in the sense of the first-order SD. In short, our results confirm that option introduction improves significantly the performance of unhedged portfolios, especially buying ITM protective put. 


\section{Mean-variance approach versus stochastic dominance}

Mean-variance efficient sets (Markowitz 1952) derived from a Von NeumannMorgenstern quadratic utility function and from a family of normal distributions have been widely used in both economics and business to analyze choices among risky assets. However, Baron (1977) shows that preferences can be stated over mean and variance alone only if an agent has a quadratic Bernoulli utility function. On the other hand, Rothschild and Stiglitz (1970) confirm that the preferences of an expected utility maximizing agent over different distributions of wealth cannot always be consistently stated as preferences over mean and variance alone. This can only be done if restrictive assumptions are made about either the Bernoulli utility function of the agent or the specific class of distributions from which the agent must choose. Nevertheless, Hanoch and Levy (1969) state the dilemma in which the decision from MV choice criteria contradicts to that of the SD theory. Levy (1989) reveals that the MV efficient set is different from the SD efficient sets. In addition, Michaud (2003) argues that the principal limitation of classical mean-variance efficiency as a practical framework for optimal portfolio is the estimation error insensitive. They recommend to use re-sampled technique to control estimation error and to use multi-period geometric mean analysis as a practical alternative.

Besides using MV approach, contemporary finance also advocates the use of the CAPM statistics developed by Sharpe (1964), Treynor (1965) and Jensen (1969) to compare stock, option and futures performance. As these methodologies also depend on normal return distributions and quadratic utility functions, they are not appropriate if return distributions are not normal or investors’ utility functions are not quadratic.

To circumvent the limitation of the MV approach and CAPM statistics, academics recommend to employ the SD criterion developed initially by Hadar and Russel (1969), Hanoch and Levy (1969) and Rothschild and Stiglitz (1970) for decision-makers to compare different prospects as the SD approach satisfies the general utility function and take into consideration all distributional moments in the comparison. In earlier financial economics literature, some applications of SD have been noted (Porter and Gaumnitz (1972), Porter (1973) and Joy and Porter (1974)). More recently, Post (2003) focuses on portfolio diversification issues by comparing a given portfolio to a set of assets using SD efficiency in a finite empirical panel data. He shows that diversification can obtain higher power of the SD 
tests. More recently, Post and Levy (2005) analyse the SD efficiency classification of the value-weighted market portfolio relative to benchmark portfolios based on market capitalization, book-to-market equity ratio and momentum. They conclude that risk seeking can help to explain the cross-sectional pattern of stock returns.

Early empirical studies examining dominance relationships in finance as a tool of performance measurement of portfolios incorporating options include Brooks, Levy and Yoder (1987) who use various discrete SD tests to check whether investors were better when writing calls or buying puts on their portfolios. They find no SD relationships among option strategies. Other articles applying SD to compare the performance among stocks, options and futures include Booth, Tehranian and Trennepohl (1985), Clarke (1991) and Isakov and Morard (2001).

In recent years, formal SD tests have been developed. For example, Beach and Davidson (1983) propose a test of Lorenz Curve dominance to explicitly acknowledge the distribution quantiles as dependent random estimates of the underlying distribution. Beach and Richmond (1985) extend the work to adopt a multiple comparison framework in which the distributional properties follow the Studentized Maximum Modulus (SMM) distribution tabulated by Stoline and Ury (1979). Bishop, Chakraboti and Thistle (1989) apply the unionintersection techniques in a multiple comparison of the individual moment and provide asymptotically distribution-free statistical inference procedures for the Generalized Lorenz Curves.

On the other hand, without using Generalized Lorenz Curves, Anderson (1996, 2004) proposes nonparametric SD tests to compare the income distribution directly. He suggests an alternative method to estimate cumulative distribution functions by applying the trapezoidal rule to approximate the required integrals. McFadden (1989) proposes a generalized Kolmogorv-Smirnov test for the first- and second-order SD among $\mathrm{K}$ prospects based on independently and identically distributed (iid) prospects.

Most of the earlier SD tests (for example, Beach and Davidson (1983), Anderson (1996)) are based on a multiple comparison approach. Partitioning the range of the random variables into a finite set of $\mathrm{k}$ exhaustive intervals, the multiple comparison approach assesses the SD estimate on each of the intervals. These multiple hypotheses tests lead to a statistical 
size bounded by Sidák’s inequality, a refinement of Bonferroni’s inequality. This inequality states that a multivariate normal vector with mean zero and arbitrary correlations falls inside a k-dimensional cube centred at the origin. In the special case where the correlations are zero, the test statistic has the SMM distribution, an approach that Richmond (1982) applies in the construction of simultaneous confidence intervals. Given that these tests are based on Sidák’s inequality, and because the correlations may not be zero, the true size of such a multiple comparison test is likely smaller than its nominal size.

These types of tests have been criticized because the assumption that compared distributions are independently distributed and, thus, usually they are inappropriate. This criticism is pertinent for income distribution comparisons and for financial prospects comparison where different distributions are often conditioned on similar information sets held by the economic agents. With this concern in mind, Klecan, McFadden, and McFadden (1991) extend the Kolmogov-Smirnov test to obtain a new non-parametric SD test which does allow some degree of statistical dependence across space and time. They derive an upper bound on the size of the test but the test is likely inefficient because it does not explicitly take into account the dependence structure between distributions. Linton, Maasoumi and Whang (2005) further develop a more powerful SD test by relaxing the iid assumption.

On the other hand, Davidson and Duclos (DD, 2000) construct quantile estimates for the asymptotic covariance structure over successive integrals of the probability distributions. Zheng and Cushing (2001) derive a similar test, which is albeit more restrictive conditions on testing income inequality indices. Using Monte Carlo simulation to compare the performance of various nonparametric SD tests, Tse and Zhang (2004) and Wei and Zhang (2003) reveal that the SD test developed by Davidson and Duclos is one of the most powerful but yet least conservative tests. Thus, our paper will apply DD test in our study. As the SD tests developed by Linton, Maasoumi and Whang (2005) and Barrett and Donald (2003) have their advantages as well as their limitations, we further verify the DD test results by using the SD tests developed by Linton, et al and Barrett and Donald for checking. 


\section{Data and Methodology}

This study investigates the performance of strategy by incorporating the corresponding options in trading stocks or indices in the French market. We choose ten options (call and put) and their underlying stocks or indices quotations over the period from January 4 to December 31, 1999 including the seven most well-established companies, namely: Elf Aquitaine (AQ2), France Télécom (FT3), Lafarge (LG2), Michelin (ML2), Peugeot (UG), Thomson CSF (HO2), Saint-Gobain (SG3) and three French index, namely: CAC40 (PXL), DJ Euro STOXX 50 (OEX) and DJ STOXX 50 (OSX). Daily option prices are obtained from the M.O.N.E.P. (Marché des Options Négociables de Paris), and the corresponding daily stock prices are obtained from Paris Stock of Exchange (Bourse de Paris). Options are selected according to their types and moneyness degrees and are only restrained to OTM call option and ITM put options due to the superiority of these types of options in performance enhancing.

The return, $\mathrm{R}_{\mathrm{t}}$, at time $\mathrm{t}$ for the unhedged individual stock or index is defined as

$$
\mathrm{R}_{\mathrm{t}}=\frac{\mathrm{S}_{\mathrm{t}}-\mathrm{S}_{\mathrm{t}-1}}{\mathrm{~S}_{\mathrm{t}-1}}
$$

where $S_{t}$ is the stock price or index value at time t. We adopt the approaches in Morard and Naciri (1990) and Isakov and Morard (2001) to define the hedged returns of both protectiveput and covered-call strategies to take into consideration the situations in which the options are exercised when the options are ITM and the options are not exercised when the options are out of the money ${ }^{1}$.

As the transaction volume in the options market has been increased dramatically after the introduction of the options market, some academics and practitioners would believe that incorporating options in trading stocks could outperform trading stocks alone. In this paper we investigate this possibility and hence we compare the performance of adopting coveredcall writing and protective-put buying strategies with that of pure-stock (naked) position by examining their correspondence returns. We first study whether the two hedged strategies, writing OTM covered-call and buying ITM protective-put strategies, outperform the unhedged pure-stock strategy and if both hedged positions perform better than the unhedged pure stock, we then study which hedged strategy performs the better. 
To fulfil our first objective, we set the following two hypotheses:

Hypothesis C0: Writing OTM covered call does not outperform the unhedged pure-stock strategy.

Hypothesis P0: Buying ITM protective put does not outperform the unhedged pure-stock strategy.

Rejecting Hypothesis C0 implies that writing OTM covered-call strategy outperforms the unhedged pure-stock strategy while rejecting Hypothesis P0 implies that buying ITM protective-put strategy outperforms the unhedged pure-stock strategy. When both C0 and P0 are rejected, we then test the following hypothesis:

Hypothesis CP0: There is no difference between the performance of writing OTM covered call and that of buying ITM protective put.

Rejecting Hypothesis CP0 needs further examination on whether writing OTM covered-call or buying ITM protective-put strategy performs better. Rejecting any of these hypotheses will conclude that there is an anomaly in option trading that either trading call or put or both perform better than stock alone. In this paper, we employ SD to measure 'outperform' such that writing OTM covered-call (buying ITM protective-put) strategy outperforms stock if the return of writing OTM covered-call (buying ITM protective-put strategy) dominates that of stock. If this is true, then there exists an arbitrage opportunity (Bawa 1978 and Jarrow 1986) and one will increase one's wealth as well as one's utility if one shifts the investment from stock to writing OTM covered-call (buying ITM protective-put) strategy. Hence, the rejection of these hypotheses will be an important finding in options theory. To relax these strong hypotheses, we set the following weaker hypotheses:

Hypothesis C1: Risk-adverse investors do not prefer writing OTM covered call to trading the unhedged pure stock.

Hypothesis P1: Risk-adverse investors do not prefer buying ITM protective put to trading the unhedged pure stock.

Hypothesis CP1: There is no preference in writing OTM covered call and buying ITM protective put for any risk-adverse investor. 
Rejection of Hypothesis C1 (P1) implies that risk-adverse investors prefer to write OTM covered call (buy ITM protective put) than trade the unhedged pure-stock strategy. This does not mean writing OTM covered call or buying ITM protective-put strategy outperforms the unhedged pure-stock strategy, only the preference of risk-averse investors who will increase their utilities but not wealth when they shift the investment from stock to writing OTM covered call or buying ITM protective put. Similarly, rejection of Hypothesis CP1 implies that risk-adverse investors prefer to write OTM covered call or buy ITM protective put, does not mean that writing OTM covered call outperforms buying ITM protective put or vice versa.

To test the above hypotheses, we first appoint the MV criterion (Markowitz (1952), Tobin (1958)) to draw inference on the impact of both adopting call writing and put buying on pure-stock trading. For any two investments with the variables of profit or return $Y_{i}$ and $Y_{j}$ with means $\mu_{\mathrm{i}}$ and $\mu_{\mathrm{j}}$ and standard deviations $\sigma_{\mathrm{i}}$ and $\sigma_{\mathrm{j}}$ respectively, $\mathrm{Y}_{\mathrm{j}}$ is said to dominate $\mathrm{Y}_{\mathrm{i}}$ by the MV criterion if $\mu_{\mathrm{j}} \geq \mu_{\mathrm{i}}$ and $\sigma_{\mathrm{j}} \leq \sigma_{\mathrm{i}}$. To apply the MV criterion, we first compute the simple descriptive statistics including mean $(\mu)$ and standard deviation $(\sigma)$ to test the hypotheses $\mathrm{C} 0, \mathrm{P} 0$ and $\mathrm{CP} 0$ or $\mathrm{C} 1, \mathrm{P} 1$ and $\mathrm{CP} 1$. In addition, we compute the coefficient of variation $(\sigma / \mu)$, the skewness and kurtosis coefficients and the Jarque-Bera (JB) statistic for the returns of all unhedged and hedged positions.

As contemporary finance advocates the use of the CAPM statistics for portfolio construction and performance evaluation, we next apply the CAPM analysis including beta components, the Sharpe ratio, Treynor's index and the Jensen (alpha) index developed by Sharpe (1964), Treynor (1965) and Jensen (1969) to measure performance degree of each strategy. Not being reduced by diversification, Beta $(\beta)$ of the portfolio measures the marginal contribution of asset (portfolio) to total market portfolio and measures the sensitivity of its return to the movements in the market portfolio returns. The estimation requires a numbers of linear regressions for CAPM equation in the case of both hedged and unhedged portfolios for stock i as follows:

$$
\mathrm{R}_{\mathrm{i}, \mathrm{t}}-\mathrm{R}_{\mathrm{f}, \mathrm{t}}=\alpha_{\mathrm{i}}+\beta_{\mathrm{i}}\left(\mathrm{R}_{\mathrm{m}, \mathrm{t}}-\mathrm{R}_{\mathrm{f}, \mathrm{t}}\right)+\varepsilon_{\mathrm{i}, \mathrm{t}}
$$

where $\varepsilon_{i, t}$ is the i.i.d (independent and identically distributed) residual. Three performance indices; Sharpe ratio $\left(\mathrm{S}_{\mathrm{i}}\right)$, Treynor index $\left(\mathrm{T}_{\mathrm{i}}\right)$ and Jensen's alpha index $\left(\mathrm{J}_{\mathrm{i}}\right)^{2}$ are then computed. 
These methodologies depend on normal return distributions and quadratic utility functions and are not be appropriate if return distributions are not normal or investors' utility functions are not quadratic. As shown in next section, the results of the skewness and kurtosis coefficients and the JB statistic conclude all returns being studied in this paper, including both hedged and unhedged positions, are not normal. This violates the normality assumptions required in the return distribution of option for all the portfolios and suggests using an alterative approach for the analysis.

All the above statistics restricted to mainly the first two moments of the data will miss some important information like higher moments in the data. To overcome this shortcoming, we apply the Davidson and Duclos (DD, 2000) nonparametric SD DD test ${ }^{3}$ based on the whole empirical distribution of the data to test any dominance from any of the two random samples of the returns series, say $\mathrm{Y}$ and $\mathrm{Z}$ with $N_{y}$ and $N_{z}$ observations and with the corresponding cumulative distribution functions (CDFs), $F_{y}$ and $F_{z}$, the corresponding probability density functions (PDFs), $f_{y}$ and $f_{z}$, respectively. Let $D_{i}^{0}=f_{i}$ for $\mathrm{i}=\mathrm{y}, \mathrm{z}$ and let

$$
D_{i}^{k}(x)=\int_{-\infty}^{x} D_{i}^{k-1}(y) d y \quad \text { for } k=1,2,3 \text { and for } \mathrm{i}=\mathrm{y}, \mathrm{z} \text {. }
$$

For any integer $k \geq 1$, $\mathrm{Y}$ is said to dominate $\mathrm{Z}$ stochastically at order $\mathrm{k}$ (denoted by $\mathrm{Y} \succ_{\mathrm{k}} \mathrm{Z}$ ) if $\mathrm{D}_{\mathrm{Z}}^{\mathrm{k}}\left(\mathrm{x}_{\mathrm{i}}\right) \geq \mathrm{D}_{\mathrm{Y}}^{\mathrm{k}}\left(\mathrm{x}_{\mathrm{i}}\right)$ for all $\mathrm{x}$, with strict inequality for some $\mathrm{x}$. Modified from the KolmogorovSmirnov statistic, the DD statistic testing the null hypothesis $\mathrm{H}_{0}$ of the equality of $\mathrm{D}_{\mathrm{y}}^{\mathrm{k}}(\mathrm{x})=\mathrm{D}_{\mathrm{z}}^{\mathrm{k}}(\mathrm{x})$ is:

$$
\mathrm{T}^{\mathrm{k}}(\mathrm{x})=\frac{\hat{\mathrm{D}}_{\mathrm{y}}^{\mathrm{k}}(\mathrm{x})-\hat{\mathrm{D}}_{\mathrm{z}}^{\mathrm{k}}(\mathrm{x})}{\sqrt{\hat{\mathrm{V}}^{\mathrm{k}}(\mathrm{x})}}
$$

where:

$$
\begin{aligned}
& \hat{\mathrm{V}}^{\mathrm{k}}(\mathrm{x})=\hat{\mathrm{V}}_{\mathrm{y}}^{\mathrm{k}}(\mathrm{x})+\hat{\mathrm{V}}_{\mathrm{z}}^{\mathrm{k}}(\mathrm{x})-2 \hat{\mathrm{V}}_{\mathrm{y}, \mathrm{z}}^{\mathrm{k}}(\mathrm{x}) \\
& \hat{\mathrm{D}}_{\mathrm{y}}^{\mathrm{k}}(\mathrm{x})=\frac{1}{\mathrm{~N}(\mathrm{k}-1) !} \sum_{\mathrm{i}=1}^{\mathrm{N}}\left(\mathrm{x}-\mathrm{y}_{\mathrm{i}}\right)_{+}^{\mathrm{k}-1} \\
& \hat{\mathrm{D}}_{\mathrm{z}}^{\mathrm{k}}(\mathrm{x})=\frac{1}{\mathrm{~N}(\mathrm{k}-1) !} \sum_{\mathrm{i}=1}^{\mathrm{N}}\left(\mathrm{x}-\mathrm{z}_{\mathrm{i}}\right)_{+}^{\mathrm{k}-1}
\end{aligned}
$$




$$
\begin{aligned}
& \hat{\mathrm{V}}_{\mathrm{y}}^{\mathrm{k}}(\mathrm{x})=\frac{1}{\mathrm{~N}}\left[\frac{1}{\mathrm{~N}((\mathrm{k}-1) !)^{2}} \sum_{\mathrm{i}=1}^{\mathrm{N}}\left(\mathrm{x}-\mathrm{y}_{\mathrm{i}}\right)_{+}^{2(\mathrm{k}-1)}-\hat{\mathrm{D}}_{\mathrm{y}}^{\mathrm{k}}(\mathrm{x})^{2}\right] \\
& \hat{\mathrm{V}}_{\mathrm{z}}^{\mathrm{k}}(\mathrm{x})=\frac{1}{\mathrm{~N}}\left[\frac{1}{\mathrm{~N}((\mathrm{k}-1) !)^{2}} \sum_{\mathrm{i}=1}^{\mathrm{N}}\left(\mathrm{x}-\mathrm{z}_{\mathrm{i}}\right)_{+}^{2(\mathrm{k}-1)}-\hat{\mathrm{D}}_{\mathrm{z}}^{\mathrm{k}}(\mathrm{x})^{2}\right] \\
& \hat{\mathrm{V}}_{\mathrm{y}, \mathrm{z}}^{\mathrm{k}}(\mathrm{x})=\frac{1}{\mathrm{~N}}\left[\frac{1}{\mathrm{~N}((\mathrm{k}-1) !)^{2}} \sum_{\mathrm{i}=1}^{\mathrm{N}}\left(\mathrm{x}-\mathrm{y}_{\mathrm{i}}\right)_{+}^{2(\mathrm{k}-1)}\left(\mathrm{x}-\mathrm{z}_{\mathrm{i}}\right)_{+}^{2(\mathrm{k}-1)}-\hat{\mathrm{D}}_{\mathrm{y}}^{\mathrm{k}}(\mathrm{x})^{2} \cdot \hat{\mathrm{D}}_{\mathrm{z}}^{\mathrm{k}}(\mathrm{x})^{2}\right] .
\end{aligned}
$$

Note that $\mathrm{N}_{\mathrm{y}}=\mathrm{N}_{\mathrm{z}}=\mathrm{N}$ as $(\mathrm{x}, \mathrm{y})$ are paired observations.

To test for stochastic dominance, $\mathrm{H}_{0}$ has to be examined for the full support, which is empirically impossible. A compromise is to test $\mathrm{H}_{0}$ for a pre-designed finite number of values of $\mathrm{x}$. As multiple hypotheses are involved, test based on multiple comparison have to be adopted. A multiple comparison procedure is proposed by Bishop, Formby and Thistle (1992) (BFT) by employing the union-intersection test. Following BFT, we consider fixed values of $\mathrm{x}_{1}, \mathrm{x}_{2}, \ldots, \mathrm{x}_{\mathrm{k}}$ and their corresponding statistics $\mathrm{T}^{\mathrm{k}}\left(\mathrm{x}_{\mathrm{i}}\right)$ in (4) for $\mathrm{i}=1, \ldots, \mathrm{k}$ and set the following hypotheses:

$$
\begin{aligned}
& H_{0}: D_{y}^{k}\left(x_{i}\right)=D_{z}^{k}\left(x_{i}\right), \text { for all } x_{i} ; \\
& H_{A}: D_{y}^{k}\left(x_{i}\right) \neq D_{z}^{k}\left(x_{i}\right), \text { for some } x_{i} ; \\
& H_{A 1}: D_{y}^{k}\left(x_{i}\right) \leq D_{z}^{k}\left(x_{i}\right) \text { for all } x_{i} \text { and } H_{A 1}: D_{y}^{k}\left(x_{i}\right)<D_{z}^{k}\left(x_{i}\right) \text { for some } x_{i} ; \\
& H_{A 2}: D_{y}^{k}\left(x_{i}\right) \geq D_{z}^{k}\left(x_{i}\right) \text { for all } x_{i} \text { and } H_{A 1}: D_{y}^{k}\left(x_{i}\right)>D_{z}^{k}\left(x_{i}\right) \text { for some } x_{i}
\end{aligned}
$$

To control for the probability of rejecting the overall null hypothesis, according to BFT, we use the Studentized Maximum Modulus (SMM) distribution with $\mathrm{m}$ and infinite degrees of freedom, denoted by $M_{\infty}^{k}$. The 1- $\alpha$ percentile of $M_{\infty}^{k}$, denoted by $M_{\infty, \alpha}^{k}$, is tabulated by Stoline and Ury (1979) and the following decision rules are adopted:

a) If $\left|T^{k}\left(x_{i}\right)\right|<M_{\infty, \alpha}^{k}$ for $\mathrm{i}=1, \ldots, \mathrm{k}$, accept $\mathrm{H}_{0}$.

b) If $-T^{k}\left(x_{i}\right)>M_{\infty, \alpha}^{k}$ for some i and $T^{k}\left(x_{i}\right)<M_{\infty, \alpha}^{k}$ for all $\mathrm{i}$, accept $\mathrm{H}_{\mathrm{A} 1}$.

c) If $T^{k}\left(x_{i}\right)>M_{\infty, \alpha}^{k}$ for some i and $-T^{k}\left(x_{i}\right)<M_{\infty, \alpha}^{k}$ for all $\mathrm{i}$, accept $\mathrm{H}_{\mathrm{A} 2}$.

d) If $T^{k}\left(x_{i}\right)>M_{\infty, \alpha}^{k}$ for some i and $-T^{k}\left(x_{i}\right)>M_{\infty, \alpha}^{k}$ for some i, accept $\mathrm{H}_{\mathrm{A}}$. 
DD test compares the distributions at a finite number of grid points. The choice of grid points (k) is guided by the results of various studies. Barrett and Donald (2003) and Tse and Zhang (2004) show that the reasonable choice of $\mathrm{k}$ for reasonably large samples is from 6 to 15. Too few grids will miss information of the distributions between any two consecutive grids (Barrett and Donald (2003), and too many grids will violate the independence assumption required by the SMM distribution (Richmond (1982)). In order to make more detailed comparisons without violating the independence assumption, we make 20 partitions in each comparison to check the consistency of the magnitudes and the signs of the DD statistics between two major consecutive partitions. Statistical inference is based on the SMM distribution for $\mathrm{k}=10$ and an infinite degrees of freedom ${ }^{4}$.

\section{Empirical results and implications}

The simple descriptive statistics including mean $(\mu)$, standard deviation $(\sigma)$, the coefficient of variation $(\sigma / \mu)$, skewness, kurtosis and the JB statistics for the returns of both unhedged and hedged positions are reported in Table I for each stock or index.

Table I: Descriptive statistics of returns on unhedged and hedged stock or index

\begin{tabular}{|c|c|c|c|c|c|c|c|c|c|c|c|c|}
\hline & \multirow{2}{*}{$\begin{array}{c}\mathrm{AQ} 2 \\
0.0021\end{array}$} & \multirow{2}{*}{\begin{tabular}{|c|} 
FT3 \\
0.0029
\end{tabular}} & \multirow{2}{*}{$\begin{array}{c}\mathrm{HO} 2 \\
0.0041\end{array}$} & \multirow{2}{*}{\begin{tabular}{|c|} 
LG2 \\
$0.0016^{* *}$ \\
\end{tabular}} & \multirow{2}{*}{$\begin{array}{c}\text { SG3 } \\
0.002\end{array}$} & \multirow{2}{*}{\begin{tabular}{c|} 
ML2 \\
0.0008
\end{tabular}} & \multirow{2}{*}{\begin{tabular}{|c|}
$\mathrm{UG}$ \\
$0.0023 * *$ \\
\end{tabular}} & \multirow{2}{*}{\begin{tabular}{|c|} 
PXL \\
$0.0017^{* *}$ \\
\end{tabular}} & \multirow{2}{*}{\begin{tabular}{|c|} 
OEX \\
$0.0016^{* *}$ \\
\end{tabular}} & \multirow{2}{*}{\begin{tabular}{|c|} 
OSX \\
$0.0015^{* *}$
\end{tabular}} & \multirow{2}{*}{\begin{tabular}{|r} 
Average \\
0.0021
\end{tabular}} \\
\hline \multirow{6}{*}{$\begin{array}{l}\text { Unhedged Position : } \\
\text { pure-stock strategy }\end{array}$} & Mean $(\mu)$ & & & & & & & & & & & \\
\hline & Std. Dev $(\sigma)$ & 0.029 & 0.025 & 0.028 & 0.012 & 0.023 & 0.024 & 0.019 & 0.012 & 0.012 & 0.012 & 0.018 \\
\hline & $\sigma / \mu$ & 13.53 & 9.05 & 7.05 & 7.95 & 11.82 & 29.63 & 8.48 & 7.13 & 7.95 & 8.34 & 10.82 \\
\hline & Skewness & $1.47 * *$ & $0.33^{* *}$ & 0.04 & -0.03 & $0.46^{* *}$ & $1.01 * *$ & 0.17 & 0.06 & -0.03 & -0.12 & 0.21 \\
\hline & Kurtosis & $13.16^{* *}$ & $3.38 * *$ & $3.26 * *$ & $5.02 * *$ & 3.10 & $5.83 * *$ & $3.90^{* *}$ & 3.04 & 3.02 & $3.26^{* *}$ & 3.76 \\
\hline & JB & $11.85^{* *}$ & $5.26 * *$ & $5.34 * *$ & $43.58^{* *}$ & $4.42 * *$ & $128.40 * *$ & $5.98^{* *}$ & $3.33 * *$ & $3.58 * *$ & $5.30 * *$ & 22.80 \\
\hline \multirow{6}{*}{$\begin{array}{l}\text { Hedged Position: } \\
\text { writing OTM covered - } \\
\text { call strategy }\end{array}$} & Mean $(\mu)$ & $0.1315 *$ & $0.0885 *$ & $0.0753^{*}$ & $0.1201 *$ & $0.1213^{*}$ & $0.077^{*}$ & $0.0382 * *$ & 0.0593* & $0.0395 *$ & $0.0339 *$ & 0.0785 \\
\hline & Std. Dev $(\sigma)$ & 0.086 & 0.090 & 0.100 & 0.093 & 0.129 & 0.145 & 0.033 & 0.071 & 0.040 & 0.022 & 0.081 \\
\hline & $\sigma / \mu$ & 0.65 & 1.01 & 1.33 & 0.77 & 1.07 & 1.89 & 0.86 & 1.19 & 1.01 & 0.64 & 1.04 \\
\hline & Skewness & $-0.36^{* *}$ & 0.14 & $-0.53 * *$ & $0.64 * *$ & 0.22 & $0.72 * *$ & 0.00 & 0.01 & $1.44^{* *}$ & $0.81^{* *}$ & 0.31 \\
\hline & Kurtosis & $4.45^{* *}$ & $3.52 * *$ & $4.39 * *$ & $5.99 * *$ & $6.84^{* *}$ & $3.29 * *$ & $10.23 * *$ & $10.34^{* *}$ & $5.18 * *$ & $6.53 * *$ & 6.08 \\
\hline & JB & $8.63 * *$ & $57.89 * *$ & $32.95^{* *}$ & $17.82^{* *}$ & $2.47^{*}$ & $27.81 * *$ & $662.84 * *$ & $807.14 * *$ & $138.60 * *$ & $160.44 * *$ & 191.66 \\
\hline \multirow{6}{*}{$\begin{array}{c}\text { Hedged Position: } \\
\text { buying ITM protective - } \\
\text { put strategy }\end{array}$} & Mean $(\mu)$ & $0.250^{*}$ & $0.1362 *$ & $0.156^{*}$ & $0.115^{*}$ & $0.0887 *$ & $0.2165^{*}$ & 0.0917* & 0.0414* & $0.0678^{*}$ & $0.0854^{*}$ & 0.1249 \\
\hline & Std. Dev $(\sigma)$ & 0.215 & 0.112 & 0.196 & 0.074 & 0.098 & 0.186 & 0.064 & 0.065 & 0.056 & 0.022 & 0.109 \\
\hline & $\sigma / \mu$ & 0.85 & 0.82 & 1.26 & 0.65 & 1.11 & 0.86 & 0.70 & 1.59 & 0.83 & 0.26 & 0.89 \\
\hline & Skewness & $0.57 * *$ & $0.75^{* *}$ & 0.29 & $0.51^{* *}$ & $0.63^{* *}$ & $0.46^{* *}$ & $1.49 * *$ & $5.02 * *$ & 0.28 & $-0.72 * *$ & 0.93 \\
\hline & Kurtosis & 2.16 & $4.30^{* *}$ & $6.63 * *$ & 3.02 & 1.90 & $3.74 * *$ & $5.93 * *$ & $42.80^{* *}$ & 2.76 & $10.40^{* *}$ & 8.36 \\
\hline & JB & $21.21^{* *}$ & $25.14^{* *}$ & $23.32 * *$ & $11.37^{* *}$ & $29.89 * *$ & $25.76^{* *}$ & $186.00^{* *}$ & $178.39 * *$ & $4.05^{* *}$ & $602.84 * *$ & 110.80 \\
\hline
\end{tabular}

$* p<5 \%, * * p<1 \%$.. Note: the critical values for testing skewness at the 5 percent level are \pm 0.153 while the critical values for testing kurtosis are $3 \pm 0.615$. * and ** reported in the skewness and kurtosis are for normality test. 
The results in Table I show increase in both mean and standard deviation of the returns for each stock or index from the unhedged to the two-hedged positions: writing OTM covered call and buying ITM protective put. The increase in mean return for ITM protective-put strategy can be explained by the combination of the leverage effect ${ }^{5}$ and the exercise gain. This gain is usually able to compensate negative changes of the underlying prices and the premiums paid to buy option contracts. Comparing both ITM protective put and OTM covered call with naked stock strategy, the average statistics show that the ITM protective put obtains the highest mean return and the highest standard deviation $(\mu=0.1249$ and $\sigma=0.109)$, followed by the OTM covered call ( $\mu=0.0785$ and $\sigma=0.081$ ) while the naked stock strategy hold the smallest mean and the smallest standard deviation $(\mu=0.0021$ and $\sigma=0.018)$. Hence, we conclude none of these three strategies dominate one another by the MV criterion.

In addition, comparing with the unhedged position, Table I shows that the optimal risk return performance measured by $\sigma / \mu$ coefficient decreases when adopting either hedged strategies. This implies that the increase in mean return is higher than the increase in volatility by introducing option in the trading strategy. To be more precise, the table shows that ITM protective put reveals the lowest coefficient of variation; followed by the OTM covered call while the naked stock strategy has the highest coefficient of variation. This infers that the ITM protective put is preferred to the OTM covered-call strategy which, in turn, is preferred to the naked stock strategy in the risk variation criterion.

After introducing ITM put option to pure-stock or index trading strategy, the table shows that 80 percent of the skewness coefficients increase and 90 percent are positive, this is consistent with the findings in Bookstaber and Clarke (1981, 1984) that introducing ITM put option alters stock return distribution by giving more weight on the right-hand side of the distribution. In addition, by introducing the OTM call option, 70 percent of the skewness coefficients decrease but most of them still remain positive and the average coefficient appears to be higher to that of the unhedged case. This suggests OTM call introduction may also shift the stock return distribution to the right. Moreover, it is well known that options introduction will make the distribution further away from normality. The skewness coefficient reveals that 40 percent of the unhedged stocks remain normal but the OTM covered-call strategy for all stocks and indices become non-normal except FT3, SG3, UG and PXL and $80 \%$ of the ITM protective-put strategies become non-normal. Hence, we conclude that the 
options introduction makes the return distribution further away from normality. On the other hand, the results of the kurtosis coefficient show that normality is rejected for all the OTM covered call, but rejected only for 60 percent of the ITM protective-put strategy and for 70 percent of the unhedged position; this shows that the OTM covered call has relatively flatter tails on average. Nevertheless, the results of the JB statistic in Table I show that normality is rejected for all unhedged and hedged strategies with covered call and protective put, with the JB estimates increase significantly for both hedge strategies, inferring that distribution becomes more non-normal after introducing the call or put options in the trading strategies.

Table II exhibits performance by using beta coefficient, Sharpe ratio, Treynor and Jensen indices for each strategy on each stock or index. Option introduction reduces the systematic risk (beta) in 90 percent of the hedged positions. Among them, 30 percent of the beta values are negative. These results corroborate the findings of Trennepothl and Duke (1982). In addition, the Beta coefficients are less than one or even become negative, confirming the role of option on systematic risk minimisation ${ }^{7}$. Both the Sharpe ratio and the Treynor index increase and become positive for nearly all hedged positions, with the largest Sharpe ratio and the Treynor index obtained by the ITM put strategy, followed by the OTM call strategy. This implies that the ITM put is most preferable, followed by the OTM call and then pure-stock strategy in terms of the Sharpe ratio and the Treynor index. These result is due to the larger change in mean return then the change in the systematic risk by adopting call or put in trading stock. Also, the Jensen index increases for both hedged strategies, with the larger increase in the ITM protective put. This indicates that returns generated by hedged positions are higher than market return with the ITM protective put being superior to the OTM covered-call strategy, both are superior to the pure-stock strategy. From the results in the average statistics, ITM put options attain the lowest $\beta(0.25)$, followed by OTM coveredcall strategies (0.37). Similarly, the ITM protective put obtains the highest Sharpe, Treynor and Jensen indices (0.89; 0.03 and 0.104 respectively), followed by the OTM covered-call strategy (0.46; -0.04 and 0.06 respectively) while the naked stock obtains the smallest values. This confirms the superiority of ITM protective put, followed by OTM covered-call strategy by using the beta coefficient, Sharpe ratio, Treynor and Jensen indice. 
Table II: Summary of index performance measure of individual stock/index position

\begin{tabular}{|c|c|c|c|c|c|c|c|c|c|c|c|c|}
\hline & & AQ2 & FT3 & HO2 & LG2 & SG3 & ML2 & UG & PXL & OEX & OSX & Average \\
\hline \multirow{6}{*}{$\begin{array}{l}\text { Unhedged Position: } \\
\text { pure-stock strategy }\end{array}$} & Beta & 1.06 & 0.37 & 1.19 & 1.10 & 0.75 & 0.82 & 0.93 & 1.15 & 1.10 & 1.06 & 0.95 \\
\hline & Sharpe & -1.12 & -1.23 & -1.23 & -2.60 & -1.37 & -1.38 & -1.65 & -2.71 & -2.60 & -2.67 & -1.85 \\
\hline & Treynor & -0.030 & -0.086 & -0.029 & -0.030 & -0.043 & -0.041 & -0.035 & -0.029 & -0.030 & -0.031 & -0.038 \\
\hline & Jensen & 0.003 & -0.020 & 0.005 & 0.003 & -0.008 & -0.007 & -0.002 & 0.005 & 0.003 & 0.002 & -0.002 \\
\hline & $t^{*}(J)$ & 0.49 & $-3.67 *$ & 0.87 & $2.90^{*}$ & $-1.68^{*}$ & $-1.46^{* *}$ & -0.49 & $8.24^{*}$ & $2.90^{*}$ & $1.58^{* *}$ & -0.11 \\
\hline & $\mathrm{T}^{*}(\beta)$ & $6.73^{*}$ & $2.41^{*}$ & $7.90^{*}$ & $32.32 *$ & $5.63^{*}$ & $6.02 *$ & $9.12^{*}$ & $66.39 *$ & $32.32 *$ & $30.16^{*}$ & 19.90 \\
\hline \multirow{6}{*}{$\begin{array}{l}\text { Hedged Position: } \\
\text { writing OTM } \\
\text { covered-call strategy }\end{array}$} & Beta & -0.16 & 2.10 & 0.23 & -0.91 & 0.35 & -0.21 & 0.67 & 1.09 & 0.47 & 0.11 & 0.37 \\
\hline & Sharpe & 1.12 & 0.60 & 0.40 & 0.92 & 0.67 & 0.29 & 0.11 & 0.35 & 0.12 & -0.03 & 0.46 \\
\hline & Treynor & -0.60 & 0.03 & 0.18 & -0.09 & 0.25 & -0.20 & 0.01 & 0.02 & 0.01 & -0.01 & -0.04 \\
\hline & Jensen & 0.092 & 0.123 & 0.050 & 0.075 & 0.098 & 0.048 & 0.026 & 0.061 & 0.020 & 0.003 & 0.060 \\
\hline & $t^{*}(J)$ & $5.17^{*}$ & $6.81^{*}$ & $2.35 *$ & $3.98^{*}$ & $3.67^{*}$ & $1.50 * *$ & $3.92 *$ & $4.23^{*}$ & $2.47^{*}$ & 0.69 & 1.09 \\
\hline & $\mathrm{T}^{*}(\beta)$ & -0.31 & $4.02^{*}$ & 0.37 & $-1.69 *$ & 0.45 & -0.23 & $3.53^{*}$ & 2.63* & $1.97 * *$ & 0.86 & 0.20 \\
\hline \multirow{6}{*}{$\begin{array}{c}\text { Hedged Position: } \\
\text { buying ITM protective- } \\
\text { put strategy }\end{array}$} & Bêta & -1.25 & 1.08 & 0.25 & 1.07 & 0.72 & -0.81 & -0.14 & 1.02 & 0.13 & 0.45 & 0.25 \\
\hline & Sharpe & 1.00 & 0.90 & 0.62 & 1.08 & 0.55 & 0.97 & 0.88 & 0.10 & 0.59 & 2.22 & 0.89 \\
\hline & Treynor & -0.17 & 0.09 & 0.48 & 0.08 & 0.07 & -0.22 & -0.42 & 0.00 & 0.26 & 0.11 & 0.03 \\
\hline & Jensen & 0.175 & 0.137 & 0.130 & 0.126 & 0.081 & 0.178 & 0.053 & 0.057 & 0.038 & 0.066 & 0.104 \\
\hline & $t^{*}(J)$ & $3.98^{*}$ & $5.97 *$ & $3.16^{*}$ & 8.99* & $3.99 *$ & $4.65 *$ & $3.98^{*}$ & $4.31^{*}$ & $3.21^{*}$ & $13.73 *$ & 5.59 \\
\hline & $t^{*}(\beta)$ & -0.98 & $1.62^{* *}$ & 0.21 & $2.63^{*}$ & $1.40 * *$ & -0.74 & -0.36 & $3.98^{*}$ & 0.39 & $3.25 *$ & 0.22 \\
\hline
\end{tabular}

${ }^{*} p<5 \%, * * p<1 \%$.

Table III: DD stochastic dominance tests between unhedged and hedged positions for individual stock's portfolios

\begin{tabular}{|c|c|c||c|c||c|c||}
\hline $\begin{array}{c}\text { Pure-stock } \\
\text { strategy }\end{array}$ & $\begin{array}{c}\text { Writing-OTM } \\
\text { covered-call } \\
\text { strategy }\end{array}$ & $\begin{array}{c}\text { Buying ITM } \\
\text { protective-put } \\
\text { strategy }\end{array}$ & $\begin{array}{c}\text { Writing OTM } \\
\text { covered-call } \\
\text { strategy }\end{array}$ & $\begin{array}{c}\text { Pure-stock } \\
\text { strategy }\end{array}$ & $\begin{array}{c}\text { Buying ITM } \\
\text { protective-put } \\
\text { strategy }\end{array}$ & $\begin{array}{c}\text { Pure-stock } \\
\text { strategy }\end{array}$ \\
\hline AQ2 & ND & ND & AQ2 & FSD & AQ2 & FSD \\
\hline FT3 & ND & ND & FT3 & FSD & FT3 & FSD \\
\hline HO2 & ND & ND & HO2 & ND & HO2 & ND \\
\hline LG2 & ND & ND & LG2 & FSD & LG2 & FSD \\
\hline SG3 & ND & ND & SG3 & ND & SG3 & FSD \\
\hline ML2 & ND & ND & ML2 & FSD & ML2 & FSD \\
\hline UG & ND & ND & UG & FSD & UG & FSD \\
\hline PXL & ND & ND & PXL & FSD & PXL & FSD \\
\hline OEX & ND & ND & OEX & FSD & OEX & FSD \\
\hline OSX & ND & ND & OSX & FSD & OSX & FSD \\
\hline
\end{tabular}

Note that the results are read for the left toward the right. The dominance relationships test is applied between strategies placed in left column and those placed in right column. For example, the most left entry for AQ2 means that the pure-stock strategy does not stochastic dominate writing OTM covered call strategy" while the most right entry for AQ2 means that buying ITM protective put strategy dominates the pure-stock strategy in the first order. ND: No Stochastic Dominance; FSD: First Stochastic Dominance; SSD: Second Stochastic Dominance; TSD: Third Stochastic Dominance.

Table III reports the DD test results of all the unhedged and hedged positions for the entire period being studied in this paper. The results in Table III show that nearly all (except SG3 and HO2) OTM writing covered call and nearly all (except HO2) ITM protective put dominate their corresponding pure-stock strategy in the first order SD at the 1\% level. This leads us reject both Hypotheses C0 and P0 and conclude that both hedged positions (OTM writing covered call and ITM protective put) are superior to their corresponding pure-stock 
strategy. This infers that there may exist an anomaly of the existence of arbitrage opportunities in option trading that all types of non-satiated investors (prefer more to less) will increase their wealth and utilities by switching from the pure-stock strategy to their corresponding OTM writing covered-call or ITM protective-put strategies (Bawa (1978), Jarrow (1986) and Falk and Levy (1989)).

Figure 1A: The CDF of the Daily returns of AQ2 for OTM covered-call and naked stock strategies and the corresponding DD statistics: the entire period

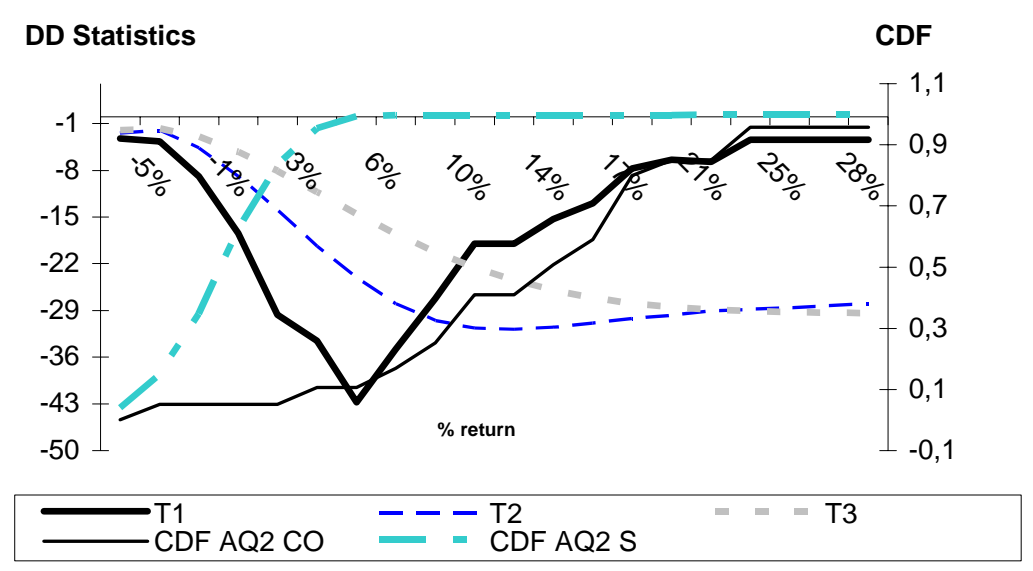

Figure 1B: The CDF of the Daily returns of AQ2 for ITM protective-put and naked stock strategies and the corresponding DD statistics: the entire period

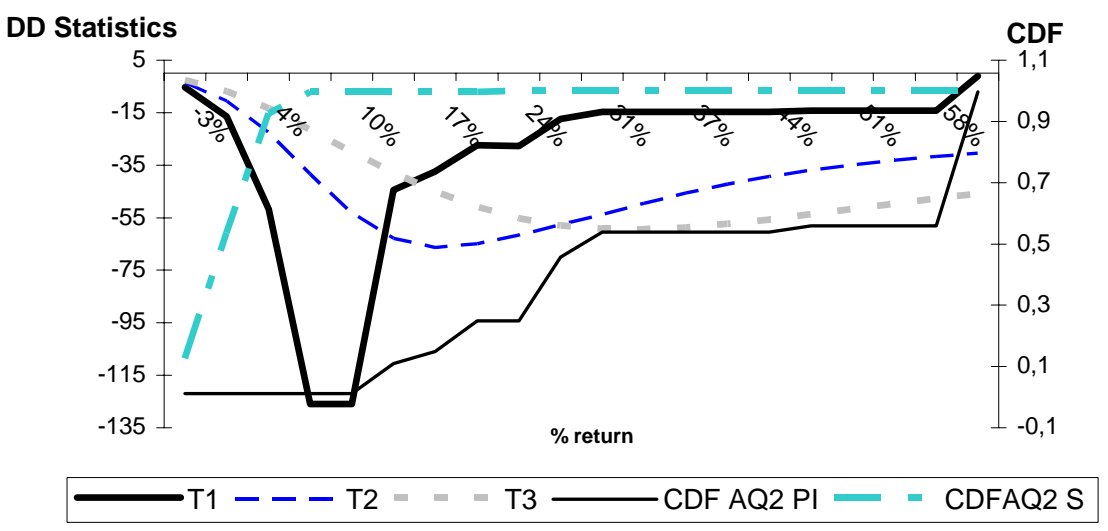

To illustrate the SD relationship, we plot the CDFs of the daily returns for the AQ2 ${ }^{8}$ unhedged pure stock with either the corresponding OTM covered-call (as shown in Figure 1A) or ITM protective-put (as shown in Figure 1B) hedged positions together and plot their corresponding DD test statistics. Figure 1A shows that in the entire period the empirical cumulative density function of the unhedged position (CDF AQ2 S) is greater than that of the OTM covered-call hedged position (CDF AQ2 CO). This implies that the cumulative 
probability on any point is greater for the unhedged position than for the OTM covered-call hedged position. Hence the covered-call position is preferred to the unhedged position in the sense of FSD for any non-satiated investor with increasing utility function. The significant dominance relationship is found in the return interval from -7 to 30 percent as all three DD statistics (T1, T2 and T3) are negative in the entire range with some portion being significant at the 1 percent level. Similarly, Figure 1B shows that any point in the CDF AQ2 S is greater than that of ITM protective-put position (CDF AQ2 PI), revealing the dominance of the ITM protective-put hedged position over the unhedged position in the sense of FSD, SSD and TSD as all the corresponding DD statistics are negative in the entire range with some portions being significant at the 1 percent level in the first three orders. These enable us to draw the conclusion that both the ITM Protective-put strategy and the OTM covered-call strategy outperform the unhedged strategy and all types of non-satiated investors with increasing utility functions prefer both ITM protective-put and the OTM covered-call strategies than the unhedged stock strategy as they will increase their wealth and utility by switching from purestock strategy to the corresponding ITM protective-put or the OTM covered-call strategies.

Table IVA: DD stochastic dominance tests between unhedged and hedged positions for individual stock/index in the first Sub-period: January to June 1999

\begin{tabular}{|c|c|c|c|c|c|c|}
\hline $\begin{array}{c}\text { Pure-stock } \\
\text { strategy }\end{array}$ & $\begin{array}{c}\text { Writing OTM } \\
\text { covered-call } \\
\text { strategy }\end{array}$ & $\begin{array}{c}\text { Buying ITM } \\
\text { protective-put } \\
\text { strategy }\end{array}$ & $\begin{array}{c}\text { Writing OTM } \\
\text { covered-call } \\
\text { strategy }\end{array}$ & $\begin{array}{c}\text { Pure-stock } \\
\text { strategy }\end{array}$ & $\begin{array}{c}\text { Buying ITM } \\
\text { protective-put } \\
\text { strategy }\end{array}$ & $\begin{array}{c}\text { Pure-stock } \\
\text { strategy }\end{array}$ \\
\hline AQ2 & $\mathrm{ND}$ & ND & AQ2 & FSD & AQ2 & FSD \\
\hline FT3 & $\mathrm{ND}$ & ND & FT3 & FSD & FT3 & FSD \\
\hline HO2 & SSD & SSD & HO2 & ND & HO2 & ND \\
\hline LG2 & $\mathrm{ND}$ & $\mathrm{ND}$ & LG2 & FSD & LG2 & FSD \\
\hline SG3 & ND & ND & SG3 & SSD & SG3 & FSD \\
\hline ML2 & $\mathrm{ND}$ & ND & ML2 & FSD & ML2 & FSD \\
\hline UG & ND & ND & UG & FSD & UG & FSD \\
\hline PXL & $\mathrm{ND}$ & ND & PXL & FSD & PXL & FSD \\
\hline OEX & ND & ND & OEX & FSD & OEX & FSD \\
\hline OSX & ND & ND & OSX & FSD & OSX & FSD \\
\hline
\end{tabular}

Refer to Table III on the notation and how to read the table.

For robustness checking, we further analyse the DD stochastic dominance relationships for two non-overlapping sub-periods ${ }^{9}$ between the hedged and unhedged positions and the results are summarized in Tables $4 \mathrm{~A}$ and $4 \mathrm{~B}$. The results in the tables lead us conclude that hypothesis $\mathrm{H}_{\mathrm{A} 1}$ is accepted for both hedged strategies in 90 percent of cases in the first sub-period and accepted in all cases in the second sub-period. This reveals that the dominance of the hedged strategies is consistent in the whole period as well as in any of these sub-periods. From the unreported figures, we find that majority of DD values are negative in the entire range with some portions being significant at the 1 percent level. This confirms the 
same FSD relationships in both sub-periods as well as in the entire period. Similar to the momentum puzzle found by Jegadeesh and Titman (1993, 2001), our results surprise us that investors do not learn from the first sub-period that the hedged positions outperform the unhedged position and hence this anomaly carries on to the second sub-period. In addition, we also conduct the test on the two overlapping periods ${ }^{10}$, drawing similar conclusions ${ }^{11}$, which implies the superiority of both covered-call and protective-put strategies to pure-stock strategy. Hence, we can draw that the same conclusion on both first and second overlapping sub-periods in the year of 1999 in French market.

Table IVB: DD stochastic dominance tests between unhedged and hedged positions for individual stock/index in the second sub-period : July to December 1999.

\begin{tabular}{||c|c|c||c|c||c|c||}
\hline $\begin{array}{c}\text { Pure-stock } \\
\text { strategy }\end{array}$ & $\begin{array}{c}\text { Writing OTM } \\
\text { covered-call } \\
\text { strategy }\end{array}$ & $\begin{array}{c}\text { Buying ITM } \\
\text { protective-put } \\
\text { strategy }\end{array}$ & $\begin{array}{c}\text { Writing OTM } \\
\text { covered-call } \\
\text { strategy }\end{array}$ & $\begin{array}{c}\text { Pure-stock } \\
\text { strategy }\end{array}$ & $\begin{array}{c}\text { Buying ITM } \\
\text { protective-put } \\
\text { strategy }\end{array}$ & $\begin{array}{c}\text { Pure-stock } \\
\text { strategy }\end{array}$ \\
\hline AQ2 & ND & ND & AQ2 & FSD & AQ2 & FSD \\
\hline FT3 & ND & ND & FT3 & FSD & FT3 & FSD \\
\hline HO2 & ND & ND & HO2 & FSD & HO2 & FSD \\
\hline LG2 & ND & ND & LG2 & FSD & LG2 & FSD \\
\hline SG3 & ND & ND & SG3 & FSD & SG3 & FSD \\
\hline ML2 & ND & ND & ML2 & SSD & ML2 & FSD \\
\hline UG & ND & ND & UG & FSD & UG & FSD \\
\hline PXL & ND & ND & PXL & FSD & PXL & FSD \\
\hline OEX & ND & ND & OEX & FSD & OEX & SSD \\
\hline OSX & ND & ND & OSX & FSD & OSX & FSD \\
\hline
\end{tabular}

Refer to Table III on the notation and how to read the table. 
Table V: DD stochastic dominance relationships between hedged positions for individual stock positions for the entire period and the two sub-periods ${ }^{12}$.

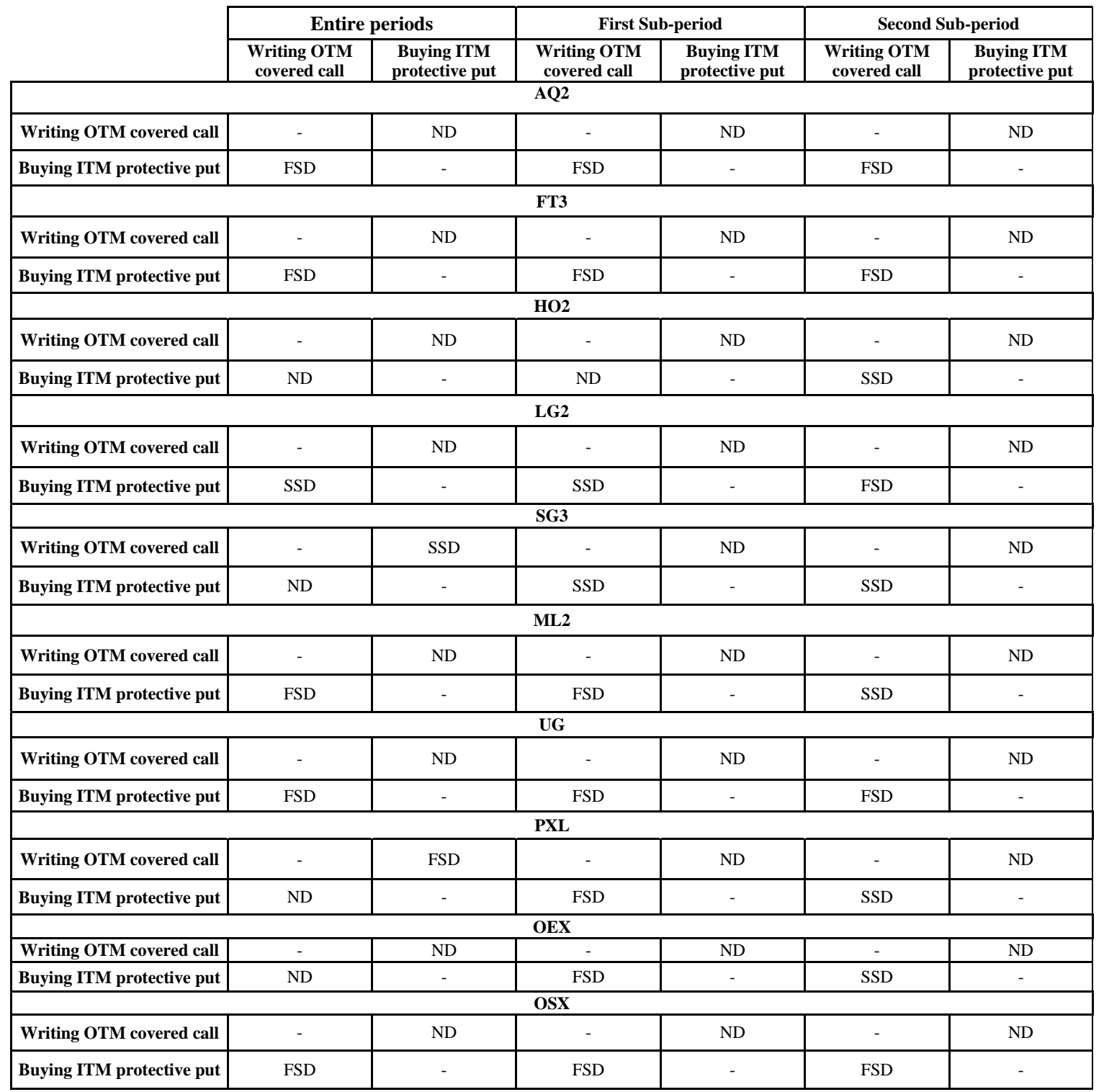

The table must be read for the left toward the right. The dominance relationships test is applied between strategies placed in left column and those placed in right column (strategy noted in left column dominates or not the strategy noted in right column).

ND: No Stochastic Dominance; FSD: First Stochastic Dominance; SSD: Second Stochastic Dominance; TSD: Third Stochastic Dominance.

As both Hypotheses C0 and P0 are rejected and both writing OTM covered call and buying ITM protective put are revealed to outperform their unhedged pure-stock strategy, we now turn to compare the performance between the two hedged strategies and report their SD relationships for the entire period as well as for the two non-overlapping sub-periods in Table V. The table exhibits that ITM protective put is superior to the OTM covered call for the entire period as the ITM protective-put strategy significantly dominates its corresponding OTM covered call in the sense of the first order in $50 \%$ of cases but only one case shows the 
significantly reversed dominance in the entire period. We also notice that among all the nonsignificant FSD cases on either direction, there exists one second-order SD for ITM put and one for OTM call. This reveals that the dominance relationship between the two hedged positions is not as clear as in the comparison with their unhedged positions, but on average the ITM protective put outperforms the OTM covered call for all the significant first-order stochastic dominance cases. A similar conclusion can be drawn in both non-overlapping subperiods as $60 \%$ (50\%) of ITM put first-order stochastically dominate their OTM covered call in the first (second) sub-period while 20\% (40\%) of ITM put second-order stochastically dominate their OTM covered call in the first (second) sub-period but none of the OTM dominates its responding ITM put in none of the first three orders. For robustness check, we compare the dominance relationship in the overlapping sub-periods ${ }^{13}$ and obtain the same superior dominance from the ITM put over the OTM call on average.

Figure 2: The CDF of the Daily Returns of AQ2 for the OTM covered-call and the ITM protective-put strategies and the corresponding DD Statistics in the entire period.

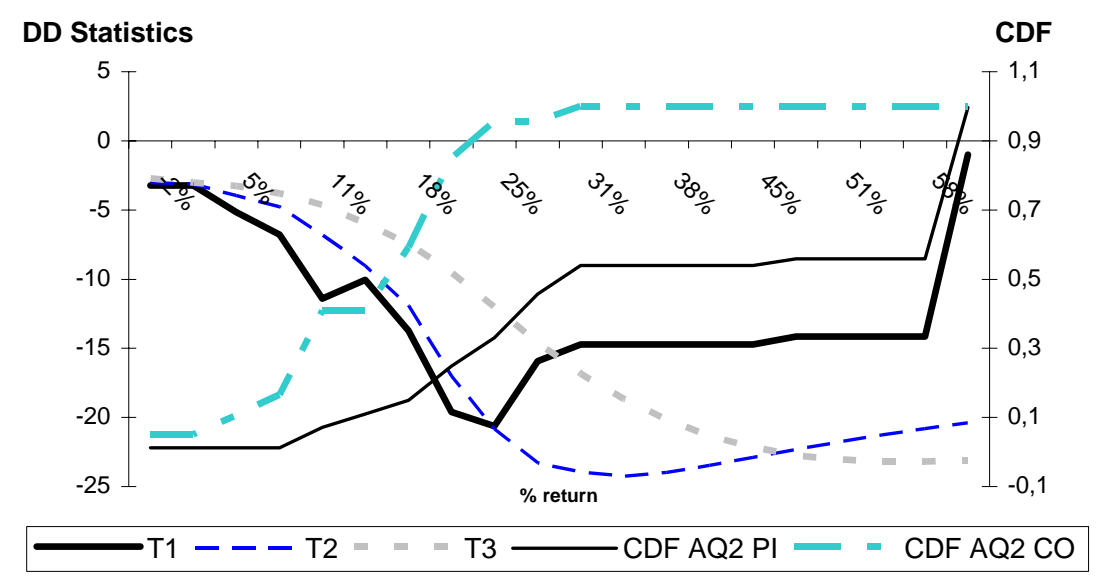

We illustrate the SD relationship by using AQ2 as example to plot the CDFs of the returns for both the ITM put and OTM call in Figure 2 and their corresponding DD statistics (T1, T2 and T3) ${ }^{14}$. The figure shows that in the entire period the empirical cumulative density function of the OTM covered-call hedged position (CDF AQ2 CO) is greater than that of the ITM protective-put hedged position (CDF AQ2 PI). This implies that the cumulative probability of any point on the OTM covered-call position is greater than that for the ITM protective-put position. This reveals that the protective-put position is preferred to the covered-call position in the sense of FSD for any non-satiated investor with increasing utility 
function. This is confirmed by all three DD statistics (T1, T2 and T3), which are negative in the entire range with some portions being significant at the 1 percent level.

At last, we apply the SD tests developed by Linton, Maasoumi and Whang (2005) and Barrett and Donald (2003) for checking. The advantage of SD test developed by Linton, Maasoumi and Whang (2005) is they relax the iid assumption while the SD test Barrett and Donald (2003) has also been found to be one of the most powerful SD test besides the DD test. As the results from SD tests developed by Linton, Maasoumi and Whang (2005) and Barrett and Donald (2003) are similar to those from DD test, we only report the DD test in this paper.

\section{Conclusion}

This study discovers new findings on the use of option strategies, including writing covered-call and buying protective-put option strategies. We compare the performance of unhedged to hedged positions for 10 main stocks or indices in French stock market. Our results show that on average the ITM protective put obtains the highest mean and the highest standard deviation, followed by the OTM covered call while the naked stock strategy hold the smallest mean and the smallest standard deviation. Hence none of these three strategies dominate one another by the MV criterion. However, our CAPM statistics show that the ITM protective put obtains the lower beta coefficient and the highest Sharpe, Treynor and Jensen indices, followed by the OTM covered-call strategy compared with the naked stock strategy. This confirms the superiority of ITM protective put, followed by OTM covered-call strategy by using the beta coefficient and other CAPM statistics.

Nevertheless, skewness and kurtosis coefficients and the JB statistic reveal that the returns of most of the hedged and unhedged stocks/indices are rejected to be normal. Thus, the conclusion drawn by MV criterion and CAPM statistics may not be reliable and hence we further conduct SD tests in the study. Our SD findings reveal that both hedged positions (writing OTM covered call and buying ITM protective put) are superior to their corresponding pure-stock strategy as the former dominates the latter in the sense of FSD. This infers that there may exist an anomaly of the existence of arbitrage opportunities in option trading that all types of non-satiated investors will increase their wealth as well as their utilities by 
switching from the pure-stock strategy to their corresponding writing OTM covered-call or buying ITM protective-put strategies. We also find that the dominance relationship between the two hedged positions is not as clear as in the comparison with their unhedged positions, but on average more ITM protective put outperforms the OTM covered call. In short, our results confirm that option introduction improve generally the performance of unhedged portfolios, especially for the case of buying ITM protective-put strategy. 


\section{Footnotes}

${ }^{1}$ Refer to Morard and Naciri (1990) and Isakov and Morard (2001) for the formula of the returns of the hedged strategies.

${ }^{2} S_{i}=\frac{R_{i}-R_{f}}{\sigma_{i}}, T_{i}=\frac{R_{i}-R_{f}}{\beta_{i}}$ and $J_{i}=\alpha_{i}=\left(R_{i}-R_{f}\right)-\beta\left(R_{m}-R_{f}\right)$.

${ }^{3}$ We also apply the SD tests developed by Linton, Maasoumi and Whang (2005) and Barrett and Donald (2003) for checking. The advantage of SD test developed by Linton, Maasoumi and Whang (2005) is they relax the iid assumption while the SD test Barrett and Donald (2003) has been found to be one of the most powerful SD test besides the DD test . As the results from SD tests developed by Linton, Maasoumi and Whang (2005) and Barrett and Donald (2003) are similar to those from DD test, we only report the DD test in this paper.

${ }^{4}$ Refer to Fong, Wong and Lean (2005) for the reasoning. Critical values are: 3.691, 3.25 and 3.043 for 1\%, 5\% and 10\% level of significance tabulated in Stoline and Ury (1979).

${ }^{5}$ Leverage effect corresponds to a negative correlation between post return and future volatility as the result of stock and option combination.

${ }^{6}$ On average, the skewness coefficient is 0.21 for naked stock and 0.93 for ITM protective-put strategy.

${ }^{7}$ The smaller the beta is weak, the less the systematic risk is weak. Hence, $\beta<1$ is preferably for risk averters.

${ }^{8}$ The plots of other stocks or indices reveal similar conclusion. Hence, we skip reporting the plots, which are available on request.

${ }^{9}$ We choose two sub-periods: the first is for January to June and the second is for July to December 1999.

${ }^{10}$ We analyse the results in the overlapping sub-periods, obtain similar results and draw the same conclusion.

We do not report the results for simplicity but they are available on request.

${ }^{11}$ The same definitions of table III are used.

${ }^{12}$ We analyse the results in the overlapping sub-periods, obtain similar results and draw the same conclusion. We do not report the results for simplicity but they are available on request.

${ }^{13}$ The results are available on request.

${ }^{14}$ The plots of other stocks or indices are available on request. Most of other plots reveal the same dominance relationships. 


\section{References}

Anderson, Gordon, (1996), Nonparametric Tests of Stochastic Dominance in Income Distributions, Econometrica, 64(5), 1183-1193.

Anderson, Gordon, (2004), Toward an empirical analysis of polarization, Journal of Econometrics, 122, $1-26$.

Baron, D. P., (1977), On the utility theoretic foundations of mean-variance analysis, Journal of Finance, 32(5), 1683-1697.

Barrett, G. and Donald, S. (2003), Consistent tests for stochastic dominance, Econometrica, 71 (1), 71-104.

Bawa, Vijay S., (1978), Safety-first, stochastic dominance, and optimal portfolio choice, Journal of Financial and Quantitative Analysis, 13, 255-271.

Beach, M. and Davidson, R., (1983), Distribution-free statistical inference with Lorenz curves and income shares, Review of Economic Studies, 50, 723-735.

Beach, M. and Richmond, J., (1985), Joint confidence intervals for income shares and Lorenz Curves, International Economic Review, 26, 439-450.

Benninga, S. and Blume, M., (1985), On the optimality of portfolio Insurance, Journal of Finance, XI (5), 1341-1352.

Bishop, A., Chakraborti, S. and Thistle, D., (1989), Asymptotically Distribution-Free Statistical Inference for generalized Lorenz Curves, Review of Economics and Statistics, 71, 725-727.

Bishop, J., Formby, J. and Thisle, J., (1992), Convergence of the South and non-South income distributions, 1969-1979, American Economic Review, 82, 262-272.

Black, F. and Scholes, M., (1973), The pricing of options and corporates liabilities, Journal of Political Economy, 81, 637-659.

Bookstaber, R. and Clarke, R., (1981), Options can alter portfolio return distributions, Journal of Portfolio Management, 7, spring, 63-70.

Bookstaber, R. and Clarke, R., (1983), An algorithm to calculate the return distribution of portfolios with option positions, Management Science, 29 (4), 419-429. 
Bookstaber, R. and Clarke, R., (1984), Option portfolio strategies: Measurement and strategies, Journal of Business, 57 (4), 469-492.

Bookstaber, R. and Clarke, R., (1985), Problems in evaluating the performance of portfolios with options, Financial Analysts Journal, January/February, 48-62.

Booth, J., Tehranian, H. and Trennepohl, G., (1985), Efficiency analysis and option portfolio selection, Journal of Financial and Quantitative Analysis, 20 (4), 435-450.

Breeden, D. and Litzenberger, R., (1978), Prices of state contingent claims implicit in option prices, Journal of Business, 51 (4), 621-652.

Brooks, R. and Hand, J., (1988), Evaluating the performance of stock portfolios with index Futures contracts, Journal of Futures Markets, 8 (1), 33-46.

Brooks, R., Levy, H. and Yoder, J., (1987), Using stochastic dominance to evaluate the performance of portfolios with options, Financial Analysts Journal, March/April, 79-82.

Castellano, R. and Giacometti, R., (2001), Performance of a Hedged Stochastic Portfolio Model in the Presence of Extreme Events, Computational Economics, 17, 239-252.

Clarke, R., (1991), Stochastic-Dominance Tests of portfolio insurance strategies, Advances in Futures and Options Research, 5, 185-202.

Cox, C., (1976), Futures trading and market information, Journal of Political Economy, 3, 1215-1237. Davidson, R. and Duclos, J. Y., (2000), Statistical Inference for the measurement of the incidence of taxes and transfers, Econometrica, 52 (6), 761-776.

Dybvig, P. and Ingersoll, J., (1982), Mean-Variance theory in complete markets, Journal of Business, 55 (2), 233-251.

Fong, W.M., Wong, W.K. and Lean, H.H., (2005), Stochastic Dominance and the Rationality of the Momentum Effect across Markets, Journal of Financial Markets, 8, 89-109.

Hadar, J. and Russel, R., (1969), Rules for ordering uncertain prospects, American Economic Review, 59, 25-34.

Hakanson, N., (1978), Welfare Aspects of options and supershares, Journal of Finance, 33, 759-776.

Hanoch, G. and Levy, H., (1969), The Efficiency Analysis of Choices Involving Risk, Review of Economic studies, 36, 335-346. 
Isakov, D. and Morard, B., (2001), Improving portfolio performance with option strategies: Evidence from Switzerland, European Financial Management, 7 (1), 73-91.

Jarrow, R., (1986), The relationship between arbitrage and first order stochastic dominance, Journal of Finance, 41, 915-921.

Jensen, M.C., (1969), "Risk, the pricing of capital assets and the evaluation of investment portfolios”, Journal of Business, 42, 167-247.

Joy, O. M. and Porter, R.B., (1974), Stochastic dominance and mutual fund performance, Journal of Financial and Quantitative Analysis, 9, 25-31.

Klecan, L., McFadden, R. and McFadden, D. (1991), A robust test for stochastic dominance, Working paper, Department of Economics, University of California at Berkeley.

Levy, H., (1989), Two-Moment decision models and expected utility maximization comment, American Economic Review, 79 (3), 597-600.

Linton, O., Maasoumi, E. and Whang, Y-J. (2005). Consistent testing for stochastic dominance under general sampling schemes. Review of Economic Studies, 72, 735-765.

Markowitz, H., (1952), Portfolio selection, Journal of Finance, 7, 77-91.

McFadden, D. (1989), Testing for stochastic dominance, in Part II of T. Fomby and T.K. Seo (eds.) Studies in the Economics of Uncertainty (in honour of J. Hadar), Springer-Verlag.

Michaud, R., (2003), A practical framework for portfolio choice, Journal of Investment Management, $1(2), 1-16$.

Morard, B. and Naciri, A., (1990), Options and investment strategies, Journal of Futures Markets, 10 (5), 505-517.

Porter, R.B., (1973), An empirical comparison of stochastic dominance and mean-variance portfolio choice criteria, Journal of Financial and Quantitative Analysis, 8, 587-608.

Porter, R.B. and Gaumnitz, J.E., (1972), Stochastic dominance vs. mean-variance portfolio analysis: an empirical evaluation, American Economic Review, 62, 438-446.

Post, T., (2003), Empirical tests for stochastic dominance efficiency. Journal of Finance, 58, 19051931. 
Post, T. and Levy, H., (2005). Does Risk Seeking Drive Asset Prices? Review of Financial Studies, 18(3), 925-953.

Richmond, J., (1982), A General method for constructing simultaneous confidence intervals, Journal of the Americal Statistical Association, 77, 455-460.

Ross, S., (1976), Options and efficiency, Quarterly Journal of Economics, 90, 75-89.

Rothschild, M. and Stiglitz, J.E., (1970), Increasing risk: A definition, Journal of Economic Theory, 2, 225-243.

Sharpe, W.F., (1964), “Capital asset prices: theory of market equilibrium under conditions of risk”, Journal of Finance, 19, 452-442.

Stoline, M.R. and Ury, H.K., (1979), Tables of the studentized maximum modulus distribution and an application to multiple comparisons among means, Technometrics, 21, 87-93.

Tobin, J. (1958), "Liquidity preference and behavior towards risk”, Review of Economic Studies, 25, 65-86.

Trennepohl, G. and Dukes, W., (1981), An empirical test of option writing and buying strategies utilizing in-the-money and out-of-the-money contracts, Journal of Business Finance \& Accounting, 8 (2), 185-202.

Trennephol, G. and Dukes, W., (1982), Measuring portfolio risk in option, Journal of Financial and Quantitative Analysis, 3, 392-409.

Treynor, J.L., (1965), ow to rate management of investment funds, Harvard Business Review, 43, 6375.

Tse, Y.K. and Zhang, X. (2004). A Monte Carlo Investigation of Some Tests for Stochastic Dominance. Journal of Statistical Computation and Simulation, 74, 361-378.

Wei, S. and Zhang, C., (2003), Statistical and economic significance of stock return predictability: a mean-variance analysis, Journal of Multinational Financial Management, 13, 443-463.

Zheng, B. and Cushing, B. J., (2001), Statistical Inference for Testing Inequality Indices with Dependent Samples, Journal of Econometrics, 101 (2), 315-335. 